acetate was added as pellets to the afternoon feed. The animals, which had been reared normally until weaning at about $30 \mathrm{lb}$. live-weight, were then all placed on the control diet; the full experimentel feeding commenced at $50 \mathrm{lb}$. weight. They made satisfactory growth and exhibited no unusual external symptoms up to the time of slaughter at $210 \mathrm{lb}$. weight, after an experimental period of 120 days.

After slaughter at a bacon factory, the carcases were commercially graded, and samples of fat removed for analyses. The back-fats of group $B$ were deep yellow-brown in colour and with a slightly 'oxidized' odour; the carcases were condemned as unfit for curing. The back-fats of the remaining pigs were normal in appearance and the carcases were passed through all stages of curing.

The average peroxide values ${ }^{5}$ of whole samples of extracted loin back-fat from groups $A, B$ and $C^{\prime}$ were 0,5 and 0 respectively, while the induction periods ${ }^{6}$ were 72,12 and 17 and the iodine values 57,74 and 80 . Determinations of vitamin $\mathrm{E}^{7}$ gave figures of $3 \cdot 0,0$ and $2.8 \mathrm{mgm} . / 100 \mathrm{gm}$. Examination of the brown pigment in the fat samples from group $B$ suggests that it is similar to that described by Dam and Granados ${ }^{3}$ in connexion with vitamin E-deficient rats and chicks. Moreover, there is reason to believe that it is also related to the discoloration of carcases occasionally encountered commercially when pigs have been fed diets containing high levels of fish oils.

Agricultural Chemistry Department,
Queen's University, Belfast, K. L. RoBInson W. E. COEY

Ministry of Agriculture (N.I.), and

Agricultural Research Institute (N.I.), Hillsborough, Co. Down. July 10.

${ }^{1}$ Dam, H., J. Nutrit., 27, 193 (1944).

2 Granados, H., Aaes-Jørgensen, E., and Dam, H., Brit. J. Nutrit., 3, 322 (1949).

3 Dam, H., and Granados, H., Acta Physiol. Scand., 10, 162 (1945).

- Braudé, R., and Foot, A. S., J. Agric. Sci., 32, 71 (1942).

${ }^{5}$ Lea, C. H., Food Invest. Bd., Special Rep. 46, 107 (1938).

${ }^{6}$ Lea, C. H., Rep. Food Invest. Bd., 28 (1939).

"Tosic, J., and Moore, T., Biochem. J., 39, 498 (1945).

\section{Cholinesterase Inhibition by Parathion in vivo}

We have shown ${ }^{1}$ that 00-diethyl-O-p-nitrophenyl thiophosphate, an insecticidal compound generally known as parathion or E605, has not, when pure, any measurable in vitro inhibition of rat's brain cholinesterase. Nevertheless, pure parathion is a powerful inhibitor of cholinesterase in vivo, and there is little doubt that its mammalian toxicity is due to this property. When parathion is administered intraperitoneally to male rats $(180-220$ gm.) the dose necessary to produce a 50 per cent inhibition of brain cholinesterase within $30 \mathrm{~min}$. is about $1.5 \mathrm{mgm}$. $/ \mathrm{kgm}$., a figure of the same order as that required for OS-diethyl-O-p-nitrophenyl thiophosphate, the S-ethyl isomer of parathion, which is a highly active in vitro inhibitor ${ }^{1}$. With a dose of $3 \mathrm{mgm} . / \mathrm{kgm}$. the onset of the typical symptoms of parasympathetic stimulation occurs within 10 min. with both compounds. The cholinesterase activity of rat's blood, which is mainly due to specific enzyme in the red cells, is also unaffected by parathion in vitro; but in vivo it can readily be completely inhibited by injected parathion. There is, however, a slight but significant difference between the action of parathion and its S-ethyl isomer in vivo; when a dose of the former, which produces complete inhibition, is administered intravenously, there is a lag of a few minutes before the inhibition develops, whereas with the same dose of the latter the inhibition reaches completion very rapidly after injection.

These observations lead to the hypothesis that parathion undergoes a change to an active inhibitor after injection, and in confirmation of this it has been found that rat's blood may readily be inhibited by parathion in vitro in the presence of liver slices or homogenate. For example, $5 \mathrm{ml}$. heparinized whole blood was incubated at $37^{\circ} \mathrm{C}$. with $2.5 \mathrm{gm}$. liver slices and $0.0056 \mathrm{ml}$. parathion solution $(1.5$ per cent in ethanol), added by means of a micrometer syringe; the cholinesterase activity of the blood was completely inhibited within $10 \mathrm{~min}$. The presumed metabolite must be very unstable in blood, for if inhibited blood is withdrawn from a dosed animal it is not capable of inhibiting further cholinesterase added to it, nor does partly inhibited blood undergo a decrease in activity when incubated in vitro.

The inference from this investigation is that parathion administered to a rat is rapidly converted by the liver to an unstable cholinesterase inhibitor. Experiments previously performed in this Laboratory on hepatectomized rats by Dr. M. W. Goldblatt and $\mathrm{Mr}$. J. Frodsham have indicated that the liver cannot be the sole site of such a presumed metabolic change, for when it has been removed a rat is not less sensitive to parathion. Moreover, the miotic effect observed when parathion is instilled into a rabbit's eye suggests that an active cholinesterase inhibitor is produced in the region of that organ. Experiments at present in progress with muscle and other tissues have not so far yielded positive results. W. M. DIGGLE J. C. GAGE

Industrial Hygiene Research Laboratory,

Imperial Chemical Industries, Ltd., The Frythe, Welwyn, Herts. June 28.

${ }^{1}$ Diggle, W. M., and Gage, J. C., Biochem. J., 49, 491 (1951).

\section{'Double-Action' of Trichothecin and its Production in Soil}

Trichothecin was the name given by Freeman and Morrison ${ }^{1}$ to a stable antifungal agent produced by Trichothecium roseum. They report the ability of this antibiotic to withstand boiling, and it has been found here that its activity is unaffected by autoclaving for $1 \mathrm{hr}$. at $20 \mathrm{lb}$./sq. in. pressure on three successive occasions. This marked thermostability and the neutral reaction of trichothecin have prompted its use in this laboratory for studies on antibiotic production in the soil; Fusarium oxysporum var. cubense was the test fungus used and the lethal dose 90 was adopted as the activity unit.

A technique was devised for the study of the effect of an antibiotic on mycelial growth as apart from the effect on spore germination and subsequent growth. A standard amount of the test fungus (mycelium on agar) was placed at the centres of a series of plates, 